\title{
Characterization of Energy Vectors, in Solar Water Heaters with PCMs for Social Interest Housing
}

\author{
Alvaro Aguinaga ${ }^{1}$, Estefanía Orquera $^{2}$, Carlos Avila $^{3}$, Víctor Hidalgo $^{4}$ \\ ${ }_{1,2,4}$ Department of Mechanical Engineering \\ ${ }^{3}$ Department of Civil and Environmental Engineering \\ Escuela Politécnica Nacional \\ Ladrón de Guevara E11-253, Quito, Ecuador \\ alvaro.aguinaga@epn.edu.ec, estefania.orquera@epn.edu.ec, carlos.avila@epn.edu.ec, victor.hidalgo@epn.edu.ec
}

\begin{abstract}
This project seeks to optimize the use of energy vectors that are part of solar collectors, increasing the thermal efficiency in water heating with the use of integrated photonic solar reflectors; and in the other hand, the energy efficiency in insulated hot water tanks, with the use of phase change materials (PCMS). This paper presents the results corresponding to the generation of the group of functional variables, mathematical modelling and computational simulation, for the thermal and thermodynamic processes in the heater storage unit of a solar water heater system. For which it is necessary to perform the characterization, mathematical modelling, computational simulation, experimental validation, analysis of sensitivity and optimization of its thermal and thermodynamic processes that intervene in these elements, all of the above focused on benefiting of social interest households. The results of this applied research open a wide range of possibilities to generate innovation projects of national interest in the future. This project has the potential to transform our ability to understand the fundamental behaviour of heating processes and energy storage, using energy vectors, and its usage in the design and construction of high efficiency solar collectors for social households. This research proposal is focused on energy and household issues, which have been identified as priorities in the National Development Plan, also, contributes to the strengthening of technological convergence processes that can support sectors in which the country could competitively find new markets in the region.
\end{abstract}

Keywords: Solar Collector, Energy Vector, Photonic Reflector, PCMs, Energy Efficiency

\section{Introduction}

Energy is essential to enable the life of humanity, due to activities such as transportation, agriculture, industry, etc. and societies require it as a priority to support the way of life of billions of people who demand a quality and life expectancy in accordance with the development achieved by humanity. The global energy situation is critical today, with serious problems of pollution, climate change, international conflicts motivated by access to resources, and depletion of fossil fuels. Among the great objectives and governmental priorities in Ecuador, is the change or transformation of the energy matrix towards a more efficient and environmentally friendly system.

Framed in this state policy, this is an interdisciplinary research proposal, which is aligned with the objectives and lines of research of the National Polytechnic School University of Technology (EPN), which conducts scientific and applied research to allow the use of sustainable energy vectors and improve the energy efficiency in the systems. It has the potential to transform our ability to understand the fundamental behavior of heating and energy storage processes, through the use of energy vectors, and their use in the design and construction of high efficiency solar collectors for social interest housing.

This study will be a contribution in the characterization, modelling and optimization of heating and energy storage processes, through the use of integrated photonic solar reflectors and hot water storage with phase change materials (PCMs), respectively, in high efficiency solar water heaters, used in heating of sanitary water for homes of social interest, which will have implications in diverse and scientific branches of engineering and technology. The results of this research are fundamental, applied and open a wide range of possibilities to generate, in the future, innovative projects of national interest. 
The study and identification of variables that characterize the behavior of high efficiency solar panels have implications in the generation of knowledge and technologies that will solve problems identified as relevant in the country and have the potential to motivate the development of new industrial and productive processes at the national level around energy conversion systems and social interest housing.

This research proposal is focused on energy and housing issues, which have been identified as priorities in the national development plan, also contribute to the strengthening of technological convergence processes that can support sectors in which the country could, competitively, find new markets in the region.

\section{Integrated Photonic Solar Reflectors}

Most of the solar energy is wasted in the form of heat and the technologies that achieve the capture and use of it obtain small efficiencies, limiting the use of these devices. One way to avoid wasting this energy is to use the photon recycling technology, which can contribute both: to the development of light efficiency and greatly improve the thermo-photovoltaic energy, surpassing even the current technology called LED. [1]

Nanophotonic studies that focus on the reuse of photons propose the creation of nano-layer filters of materials such as alternating silicon dioxide and tantalum dioxide, each of them, with thicknesses of less than 1/100 of a human hair. Devices created in laboratories show that only in the utilization of light, the expected efficiency exceeds $40 \%$ and to make photovoltaic roofs 19 of 20 photons are used. [2]

Considering a thermal photonic approach, it is used an integrated photonic solar reflector and a thermal emitter which have seven layers of hafnium oxide and silicon oxide, and reflects $97 \%$ of incident sunlight.[3] When they are exposed to direct sunlight, over 850 watts per square meter on a roof, the photonic radioactive cooler is chilled to 4.9 degrees Celsius below the ambient air temperature, and has a power of 40,1 watts per square meter at room temperature. [4]

On the other hand, the conversion of broadband spectrum to a narrow band of thermal emission of the spectrum with minimal losses of energy is important to make efficient environmental sensors and biosensors as well as thermophotovoltaic energy generation systems. [5] [6]

It has been shown that the intensity of the peak of emission in a device can be more than four times greater than that of a blackbody sample under the same input power and thermal management conditions, due to an increase in temperature, compared to the reference of blackbody, the emission and the angular bandwidth are narrowed by a factor of 30 and 8 , respectively. These results indicate that the energy saved by the control of thermal emissions can be recycled and concentrated to improve the intensity of the narrow peak of emission. [7]

\section{Phase Change Materials (PCMs)}

Due to the energy crisis, energy storage is very important because it is a technique to use energy in an efficient way and to use clean and renewable energy to reduce the climate impact. In a solar water heater system, the storage of thermal energy is achieved with Phase Change Materials (PCMs), using the latent heat thermal energy storage. [8]

A typical solar water heating system is usually comprised of two units, which both operate simultaneously: a solar water heater and a PCMs contained heater storage unit. During the day, a water heater normally operates by collecting solar energy to heat the water while at the same time, the PCM absorbs thermal energy and stores it within the material. During the night when sunshine is unavailable, thermal energy is retrieved from the PCM to heat the water. [9]

The efficient use of PCMs involves at least two advantages: a mass adapted to energy that can be stored and a thermal conductivity that allows heat to be transmitted through the entire material. These materials have a low thermal conductivity and when are heated, a part of the material could be a superheated liquid, while another part remains solid. [10]

The PCM technology allows to implement several efficient systems, the schematic diagram of a heater storage unit, with PCMs, using the latent heat thermal energy storage is presented in Figure 1. 


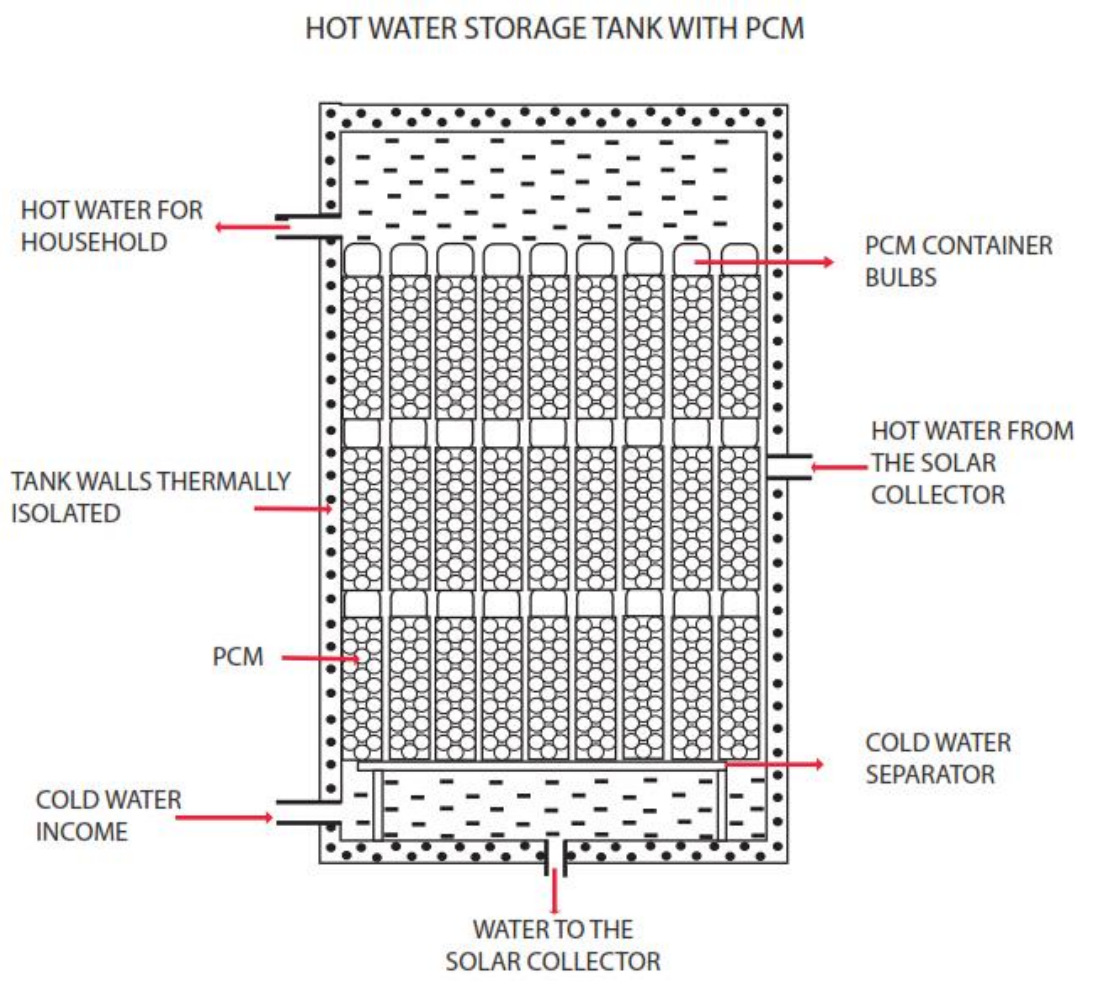

Fig. 1: Schematic diagram of a heater storage unit with PCMs.

\section{Methodology}

Based on these investigations, in this study is proposed to characterize and optimize the use of integrated photonic solar reflectors to increase the thermal efficiency to heat sanitary water; and in the other part the use of phase change materials (PCMs) in isolated hot water tanks, to achieve internal energy storage, which will improve the energy efficiency of the thermal and thermodynamic processes, in solar water heater system.

The methodology and design of this research are based on the scientific method and updated bibliographical references; so, in the development of the project the following activities should be conducted:

a. For the solar water heater system, a group of parameters must be selected, generating a group of functional variables that allow to characterize its behavior and thermal performance, for which a bibliographic review and analysis of the state of the art has been carried out.

b. Mathematical modelling of thermal and thermodynamic processes of the solar water heater system.

c. Based on initial conditions, edge and preliminary referential coefficients, the computer simulation of the mathematical models must be performed.

d. Development and instrumentation of a physical model for the experimental validation of the mathematical models.

e. Once the models have been validated, the sensitivity analysis of the parameters of the solar water heater system will be carried out.

f. The thermal efficiency will be evaluated, for different configurations of the characterized parameters, and a database is also being generated to store the information about the properties and the getting result. 
This paper presents the results corresponding to the generation of the group of functional variables, mathematical modelling and computational simulation, for the thermal and thermodynamic processes in the heater storage unit of a water heater system.

The daily cycle of heating and cooling water in the heater storage unit, with PCMs, using the latent heat thermal energy storage, of a solar water heater system is presented in Figure 2.

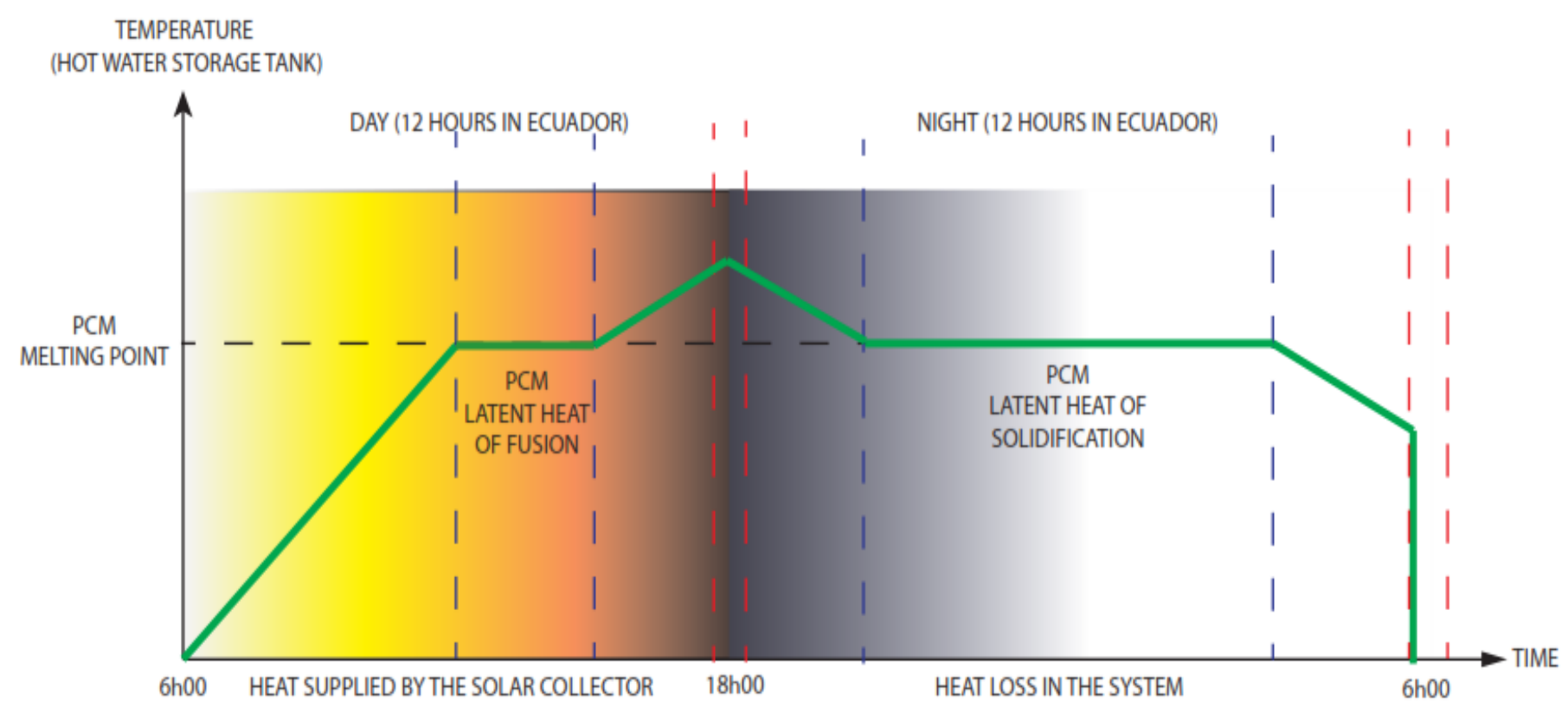

Fig. 2: Daily cycle of heating and cooling water in the heater storage unit.

In this investigation the paraffin wax has been selected as PCM, due to its thermodynamic properties, low cost and existence in the local market

The following mathematical model is proposed for the heating stage, during the day, with the heat supplied by the solar collector:

$$
\frac{\mathrm{dQ}}{\mathrm{dt}}=(\mathrm{Cpwa} * \mathrm{mwa}+\mathrm{Cppa} * \mathrm{Rmpw} * \mathrm{mwa}) * \frac{\mathrm{d} \Delta \mathrm{T}}{\mathrm{dt}}-U * A * \Delta T
$$

Where:

Q: $\quad$ Heat supplied by the solar collector $[\mathrm{kJ}]$

$\Delta \mathrm{T}: \quad$ Temperature variation in the heater storage unit $\left[{ }^{\circ} \mathrm{C}\right]$

Cpwa: Specific heat of water $\left[\mathrm{kJ} /\left(\mathrm{kg} .{ }^{\circ} \mathrm{K}\right)\right]$

Cppa: Specific heat of paraffin $\left[\mathrm{kJ} /\left(\mathrm{kg} .{ }^{\circ} \mathrm{K}\right)\right]$

mwa: Mass of water $[\mathrm{kg}]$

Rmwp: Mass ratio of paraffin to water

A: $\quad$ Outside heater storage area $\left[\mathrm{m}^{2}\right]$

$\mathrm{U}: \quad$ Overall heat loss coefficient $\left[\mathrm{kW} /\left(\mathrm{m}^{2}{ }^{\circ} \mathrm{K}\right)\right]$

Considering the dynamic system with input $\mathrm{Q}$ and output $\Delta \mathrm{T}$, it has been considered better to represent the mathematical model as a transfer function, with the frequency variable $\mathrm{s}$, as indicated below: 


$$
\frac{\Delta T(s)}{\mathrm{Q}(\mathrm{s})}=\frac{s}{(\mathrm{Cpwa} * \mathrm{mwa}+\mathrm{Cppa} * \mathrm{Rmpw} * \mathrm{mwa})-U * A}
$$

When the melting point of the paraffin wax is reached, in the heating stage, an additional heat input is required by the solar collector, which must be considered in the heating stage. The value of this added heat is equal to the specific latent heat of fusion $\mathrm{L}[\mathrm{kJ} / \mathrm{kg}]$, corresponding to the paraffin wax.

The following mathematical model is proposed, in the case of cooling during the night, considering that there is no heat supplied by the solar collector but only heat losses in the system:

$$
\frac{\mathrm{d} \Delta \mathrm{T}}{\mathrm{dt}}=\frac{-U * A * \Delta T}{\mathrm{Cpwa} * \mathrm{mwa}+\mathrm{Cppa} * \mathrm{Rmpw} * \mathrm{mwa}}
$$

Since in the cooling stage only the heat losses of the system are considered, when the solidification point of the paraffin wax is reached, the specific latent heat will be delivered, in a very long time. The equation to calculate the PCM solidification time STPCM [hours] is as follows:

$$
S T P C M=\frac{L}{U * A * \Delta T * 3600}
$$

\section{Results and Discussions}

For the computational simulation of the proposed mathematical models, it is initially necessary to determine the coefficients and properties used in the models. These values have been obtained from several papers on the subject [11] [12] [13] [14] and are presented below:

$$
\begin{aligned}
& \text { Cpwa }=4.18 \mathrm{~kJ} /\left(\mathrm{kg} .{ }^{\circ} \mathrm{K}\right) \\
& \text { Cppa }=3.26 \mathrm{~kJ} /\left(\mathrm{kg} .{ }^{\circ} \mathrm{K}\right) \\
& \text { Mwa }=1 \mathrm{~kg} \\
& \text { Rmwp }=1 \\
& \mathrm{~A}=\quad 0.2 \mathrm{~m}^{2} \\
& \mathrm{U}=\quad 0.00086 \mathrm{~kW} /\left(\mathrm{m}^{2} .{ }^{\circ} \mathrm{K}\right) \\
& \mathrm{L}=\quad 180.5 \mathrm{~kJ} / \mathrm{kg}
\end{aligned}
$$

The melting and solidification temperature of paraffin wax is set at $58{ }^{\circ} \mathrm{C}$. To simulate the proposed mathematical models, the MATLAB R2018 will be used.

To solve the mathematical model, in the heating stage (day), represented by the transfer function of equation (2), a step-type control input is considered at each hour. The result of computational simulation is presented in Figure 3. 


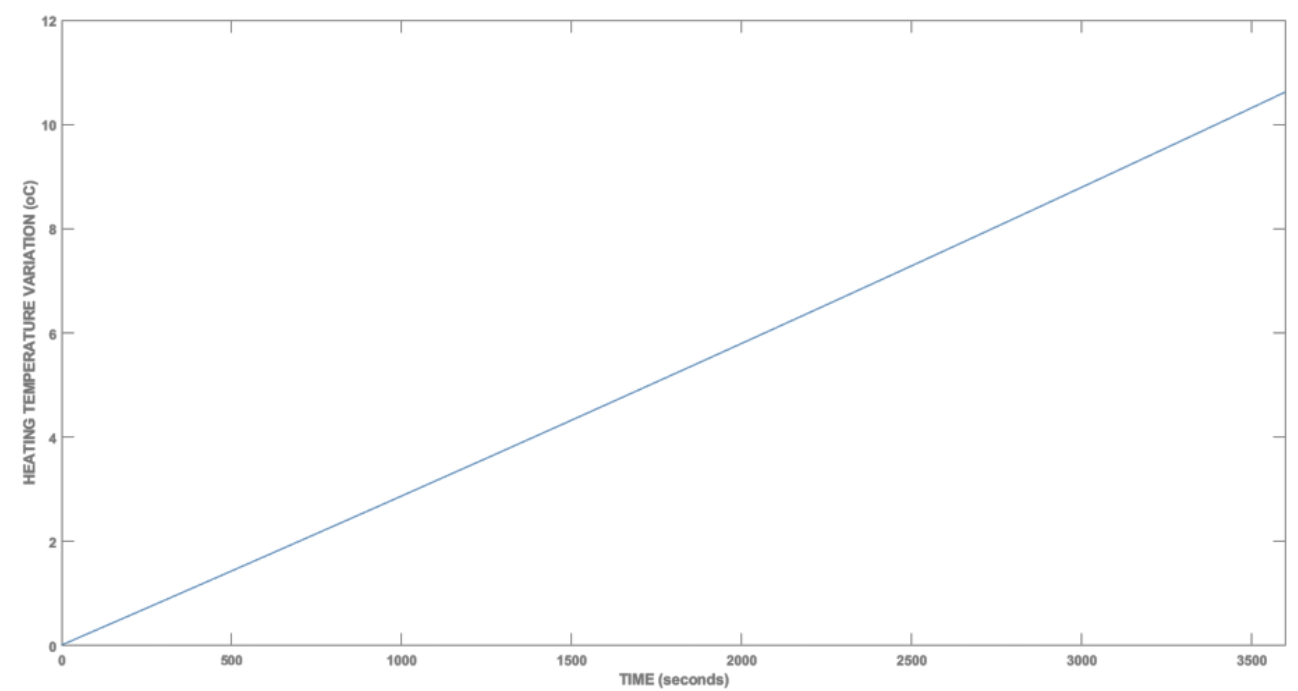

Fig. 3: Computational simulation of the mathematical model, in the heating stage (day).

The results indicate that, for the proposed model, in the heating stage (day), an increase of approximately $10{ }^{\circ} \mathrm{C}$ every hour would be achieved, for which the solar collector is required to supply an average of $76 \mathrm{~kJ}$ per hour; This is $912 \mathrm{~kJ}$ throughout the day.

Additionally, the solar collector must supply the latent heat of $180.5 \mathrm{~kJ}$ to melt the mass of PCMs, so that the minimum heat to be supplied by the solar collector during the day is approximately $110 \mathrm{~kJ}$.

Later in this research a physical model will be developed for the experimental validation of the mathematical models and their coefficients, with which, this validated model, will become a very important tool for future research and engineering designs.

To solve the mathematical model, in the cooling stage (night), represented by the differential equation (3) an initial water temperature of $70{ }^{\circ} \mathrm{C}$ is considered. The result of computational simulation is presented in Figure 4.

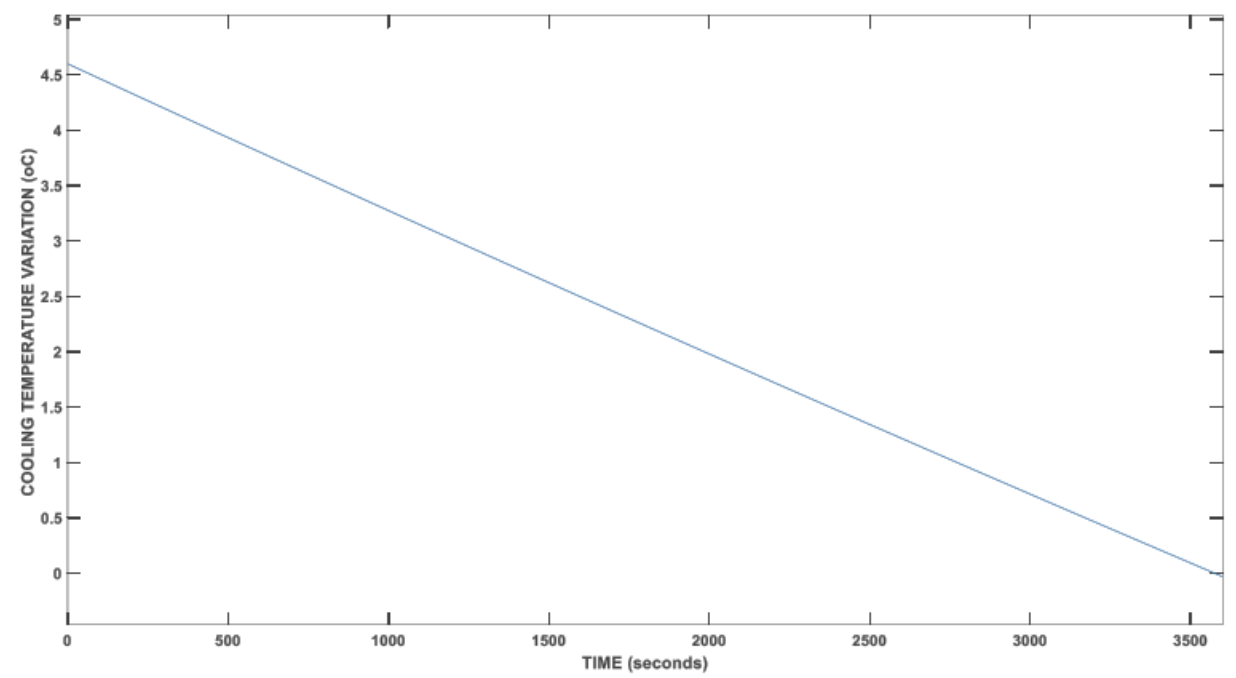

Figure 4. Computational simulation of the mathematical model, in the cooling stage (night) 
The results indicate that, for the proposed model, in the cooling stage (night), a temperature decrease of approximately $4{ }^{\circ} \mathrm{C}$ per hour would be achieved, that is, a much smaller gradient than in the day.

With these considerations, the time that the PCM would deliver its latent heat in the solidification process has been calculated; finding that it would be about 6 hours, which is a large time that would greatly improve energy efficiency.

Similarly, to the previous case, later in this research a physical model will be developed for the experimental validation of the mathematical models and their coefficients, with which, this validated model, will become a very important tool for future research and engineering designs.

\section{Conclusions}

This paper presents the results corresponding to the generation of the group of functional variables, mathematical modelling and computational simulation, for the thermal and thermodynamic processes in the heater storage unit of a solar water heater system. The notable findings are consolidated as given below:

- It has been possible to select a group of parameters, generating a group of functional variables that allow to characterize its behavior and thermal performance, for which a bibliographic review and analysis of the state of the art has been carried out.

- It has been developed mathematical modelling of thermal and thermodynamic processes in the heater storage unit of the solar water heater system.

- The results of computer simulation of mathematical models are consistent and scalable

- Later in this research a physical model will be developed for the experimental validation of the mathematical models and their coefficients, with which, this validated model, will become a very important tool for future research and engineering designs.

\section{Acknowledgements}

We would like to specially thank Escuela Politécnica Nacional, University of Technology from Quito-Ecuador, Research Project PIJ 17-09, for the financial aid and cooperation for the development of this Research Project.

\section{References}

[1] Ilic, O., Bermel, P., Chen, G., Joannopoulos, J. D., Celanovic, I., \& Soljačić, M. (2016). Tailoring high-temperature radiation and the resurrection of the incandescent source. Nature nanotechnology, vol. 11, no. 4, pp. 320-324.

[2] Cossu, M., Murgia, L., Ledda, L., Deligios, P. A., Sirigu, A., Chessa, F., \& Pazzona, A. (2014). Solar radiation distribution inside a greenhouse with south-oriented photovoltaic roofs and effects on crop productivity. Applied Energy, 133, pp. 89-100.

[3] Sheng, X., Johnson, S. G., Broderick, L. Z., Michel, J., \& Kimerling, L. C. (2012). Integrated photonic structures for light trapping in thin-film Si solar cells. Applied Physics Letters, 100(11), pp. 111110.

[4] Raman, A. P., Anoma, M. A., Zhu, L., Rephaeli, E., \& Fan, S. (2014). Passive radiative cooling below ambient air temperature under direct sunlight. Nature, 515(7528), pp. 540-544.

[5] Maruyama, S., Kashiwa, T., Yugami, H., \& Esashi, M. (2001). Thermal radiation from two-dimensionally confined modes in microcavities. Applied Physics Letters, vol. 79, no. 9, pp. 1393-1395.

[6] Bermel, P., Ghebrebrhan, M., Chan, W., Yeng, Y. X., Araghchini, M., Hamam, R., Johnson, S. G. (2010). Design and global optimization of high-efficiency thermophotovoltaic systems. Optics express, vol. 18, no. 103, pp. A314-A334.

[7] De Zoysa, M., Asano, T., Mochizuki, K., Oskooi, A., Inoue, T., \& Noda, S. (2012). Conversion of broadband to narrowband thermal emission through energy recycling. Nature Photonics, vol. 6, no. 8, pp. 535-539.

[8] Zhou, D., Zhao, C. Y., \& Tian, Y. (2012). Review on thermal energy storage with phase change materials (PCMs) in building applications. Applied energy, 92, pp. 593-605. 
[9] Mofijur, M., Mahlia, T. M. I., Silitonga, A. S., Ong, H. C., Silakhori, M., Hasan, M. H., ... \& Rahman, S. M. (2019). Phase Change Materials (PCM) for Solar Energy Usages and Storage: An Overview. Energies, vol. 12, no. 16, p. 3167.

[10] Hasse, C., Grenet, M., Bontemps, A., Dendievel, R., \& Sallée, H. (2011). Realization, test and modelling of honeycomb wallboards containing a Phase Change Material. Energy and Buildings, vol. 43, no. 1, pp. 232-238.

[11] Babar, O. A., Arora, V. K., \& Nema, P. K. (2019). Selection of phase change material for solar thermal storage application: a comparative study. Journal of the Brazilian Society of Mechanical Sciences and Engineering, vol. 41, no. 9 , p. 355.

[12] Raj, A. K., Srinivas, M., \& Jayaraj, S. (2019). CFD modelling of macro-encapsulated latent heat storage system used for solar heating applications. International Journal of Thermal Sciences, 139, pp. 88-104.

[13] Lucas, S. S., \& de Aguiar, J. B. (2019). Evaluation of latent heat storage in mortars containing microencapsulated paraffin waxes-a selection of optimal composition and binders. Heat and Mass Transfer, pp. 1-7.

[14] Cruickshank, C. A., \& Harrison, S. J. (2010). Heat loss characteristics for a typical solar domestic hot water storage. Energy and buildings, vol. 42, no.10, pp. 1703-1710. 